\title{
Baseline characteristics and response to GH replacement of hypopituitary patients previously irradiated for pituitary adenoma or craniopharyngioma: data from the Pfizer International Metabolic Database
}

\author{
D Maiter, R Abs ${ }^{1}, \mathrm{G}$ Johannsson ${ }^{2}, \mathrm{M} \mathrm{Scanlon}^{3}$, P J Jönsson ${ }^{4}, \mathrm{P}_{\text {Wilton }}^{4}$ and M Koltowska-Häggström ${ }^{4,5}$ \\ UCL St Luc Hospital, B-1200 Brussels, Belgium, ${ }^{1}$ University Hospital, Antwerp, B-2650 Edegem, Belgium, ${ }^{2}$ Sahlgrenska University Hospital, \\ SE-413 45, Göteborg, Sweden, ${ }^{3}$ University Hospital of Wales, Cardiff, United Kingdom, ${ }^{4}$ KIGS/KIMS/ACROSTUDY Medical Outcomes, Pfizer Endocrine \\ Care, SE-112 87 Stockholm, Sweden and ${ }^{5}$ Department of Pharmacy, Uppsala University, Uppsala, Sweden
}

(Correspondence should be addressed to D Maiter; Email: maiter@diab.ucl.ac.be)

\begin{abstract}
Objective: To test the hypothesis whether the effects of GH replacement therapy in adults could be affected by prior pituitary irradiation, the baseline characteristics and response to GH were evaluated in adults with severe GH deficiency (GHD), who had received or not irradiation for the treatment of pituitary adenoma or craniopharyngioma.

Design: Data from 447 patients, who had received radiotherapy (427 in addition to surgery), and 630 patients, who were operated on but not irradiated for their tumour, were retrieved from Pfizer International Metabolic Database (KIMS) and compared at baseline and 1 and 2 years following the onset of GH replacement.

Results: Irradiated and non-irradiated patients exhibited the expected phenotype of GHD at baseline. However, irradiated patients had a greater impairment in the quality of life (QoL), a higher fat mass, lower high-density lipoprotein cholesterol levels and a lower bone mineral content (BMC) than nonirradiated patients. Treatment with $\mathrm{GH}$ induced similar changes in both groups. After 1 year of $\mathrm{GH}$ replacement, there was an increase in serum IGF-I and fat-free mass, a reduction in fat mass and an improvement in QoL, all changes being equivalent in irradiated and non-irradiated patients. The lipid profile also improved with the irradiated patients showing a better response. These beneficial effects were maintained and the BMC also increased in both groups by the second year of treatment. Conclusions: This analysis shows that prior irradiation for pituitary adenoma or craniopharyngioma does not compromise the beneficial effects of GH replacement therapy.
\end{abstract}

European Journal of Endocrinology 155 253-260

\section{Introduction}

Pituitary radiation therapy is widely used as an efficient adjuvant treatment of pituitary adenomas and other perisellar tumours, predominantly to prevent regrowth of incompletely resected or relapsing tumours (1-3). Secondary brain tumours, cerebrovascular alterations and neuropsychological changes may develop as late consequences of pituitary irradiation (4-8), but the most frequent complication is hypopituitarism. The risk of developing hypopituitarism increases over time (9) and is also dependent on the dose of radiation delivered to the hypothalamic-pituitary axis, the age of the patient and the nature of the underlying deficit (10). There is evidence that such endocrine defects occur mainly at the hypothalamic rather than at the pituitary level $(2,10)$ and that the growth hormone $(\mathrm{GH})$ axis is the most sensitive to these effects, followed by the gonadotrophin and corticotrophin axes (11). Within 5 years following radiotherapy for pituitary adenoma, nearly all patients will be GH-deficient and about half would have developed panhypopituitarism $(9,10)$.

Little is known about the effects of GH replacement therapy in the subset of patients who have received prior pituitary radiation therapy, and the well-known beneficial effects of GH replacement therapy in GH-deficient adults (12-14) might be different in this particular population. Previous cranial irradiation may, indeed, induce cognitive impairment, lower quality of life (QoL) and alterations of hypothalamic-dependent functions, such as the regulation of food intake $(5,15,16)$. Such differences in baseline features of irradiated patients might significantly influence their response to $\mathrm{GH}$ therapy. We, therefore, analysed retrospectively data from Pfizer International Metabolic Database (KIMS), a pharmaco-epidemiological survey of adult GH-deficient patients, to compare both the 
baseline characteristics and the response to $\mathrm{GH}$ replacement of patients previously irradiated for pituitary adenoma or craniopharyngioma, with those of patients not given radiotherapy.

\section{Patients and methods}

\section{Patients}

The study included a total of 1107 adult patients (590 males, 517 females) enrolled in KIMS at the start of their GH replacement therapy. All patients had severe GH deficiency (GHD), defined as a peak GH level less than $3 \mu \mathrm{g} / \mathrm{l}$ on one or more validated tests of GH provocation (insulin tolerance, Arginine, glucagon or GH-releasing hormone tests) and had been treated previously for either pituitary adenoma ( $n=904 ; 487$ males) or craniopharyngioma ( $n=203 ; 103$ males). Most patients were from western European countries (91\%). In total, 477 subjects (43\% of total, 238 males) had received radiotherapy only once and at least 1 year (median, 9 years) before the onset of GH treatment (irradiated (IRR) group). Of this group, 427 patients $(90 \%)$ had been treated with a combination of surgery and radiotherapy, while 50 patients had received irradiation alone. The IRR group was compared with a group of 630 individuals ( $57 \%$ of total, 352 males) who had been operated on for their tumour but had not received irradiation (non-IRR group). Among the 477 IRR patients, the vast majority $(n=460)$ had been treated with conventional fractionated radiotherapy targeted to the sellar and/or perisellar region. Only 11 patients had received stereotactic radiosurgery and only six patients had been treated with radioactive implants. The data used were restricted to patients who had never been treated with GH (naive; $n=967$ ) or who had been treated previously with GH and had discontinued GH treatment for at least 6 months before enrolment into KIMS (seminaive; $n=140$ ) and for whom sufficient data were available at the onset or restart of GH treatment (baseline visit).

A longitudinal analysis to evaluate the effects of $\mathrm{GH}$ treatment within the same individuals was possible after 1 year of therapy in 458 patients $(n=210$, IRR; $n=248$, non-IRR) and 2 years in 264 subjects $(n=127$, IRR; $n=137$, non-IRR). The background and baseline characteristics of these subgroups of patients were not different from those found in the whole study population and baseline differences, described between IRR and non-IRR groups, were also observed when considering only patients with 1- or 2-year follow-up (data not shown).

\section{Methods}

Background data consisted of the following items: gender, age at diagnosis, adult- or childhood-onset GHD, estimated duration of GHD, age at entry into KIMS, type of pituitary adenoma and relevant medical history. History concerning the primary tumour included the number and type of surgical procedures, use and timing of radiotherapy, and number and type of other pituitary hormone deficits. Overall medical history included information on smoking, cerebrovascular and cardiovascular disease, peripheral vascular disease, hypertension, diabetes mellitus, fractures and neoplasms.

Baseline characteristics recorded at the initiation of GH treatment included weight, height, body mass index (BMI), waist circumference, hip circumference and systolic and diastolic blood pressure. Bioelectrical impedance analysis (BIA) was used to determine fat mass and fat-free mass (FFM) from equations supplied by the manufacturers, with resistance and reactance as input variables. Although less precise than other laboratory techniques, this non-invasive and rapid method has been proven to be clinically valuable to monitor changes in the body composition during $\mathrm{GH}$ therapy (17). Bone mineral content (BMC) was evaluated by dual-energy X-ray absorptiometry.

Plasma serum total cholesterol, high-density lipoprotein (HDL) cholesterol and triglycerides were measured centrally by standard methods and serum low-density lipoprotein (LDL) cholesterol was calculated (18). Serum insulin-like growth factor-I (IGF-I) was measured centrally by an HCl-extraction RIA (Nichols Institute Diagnostics, Inc., San Juan Capistrano, CA, USA). Intra-, interassay and total coefficients of variation were less than $9 \%$ in the concentration range $125-1046 \mu \mathrm{g} / \mathrm{l}$. The assay detection limit was $13.5 \mu \mathrm{g} / \mathrm{l}$. IGF-I values were adjusted for age and expressed as SDS.

QoL was assessed using the Quality of Life Assessment of GHD in Adults (QoL-AGHDA) (19). A higher score (to a maximum of 25) denotes a poorer QoL. Previous studies have shown that QoL-AGHDA can be considered as a robust measure, well suited to assess QoL in adults with GHD $(19,20)$.

Treatment with GH was started in all patients at a low dose and titrated against clinical response and IGF-I levels. Follow-up parameters available in 458 patients at 1 year and in 264 patients at 2 years were the daily GH dose and changes in IGF-I SDS, weight, BMI, waist circumference, blood pressure, body composition, serum lipids and QoL-AGHDA score.

\section{Statistical analysis}

Data analyses were performed using the Statistical Analysis System (SAS Institute, Inc., Cary, NC, USA). Significant differences between the IRR and non-IRR groups at baseline were determined by unpaired $t$-tests for normally distributed variables or by the Wilcoxon rank-sum test. The effects of $\mathrm{GH}$ treatment were analysed using paired $t$-tests or multivariate analysis for normally distributed data and by the Wilcoxon ranksum test in other cases. Comparisons of proportions 
were performed using the $\chi^{2}$ and Fischer exact tests. The analysis of baseline and follow-up data was corrected for gender and the presence of craniopharyngioma. Significance was accepted at a value of $P<0.05$ and the data are expressed as means \pm s.D. unless stated otherwise.

\section{Results}

\section{Background data}

A few background variables were different between the IRR and non-IRR groups (Table 1). Thus, in the nonIRR group, there were more male patients, the subjects were older at the time of tumour diagnosis, they had a shorter estimated duration of GHD than the IRR patients, and a higher prevalence of complete pituitary hormone deficiency $(P<0.01)$. The relative proportion of patients with craniopharyngioma was slightly higher in the non-IRR group $(21 \%)$ than in the IRR group (15\%, $P<0.01)$, while the proportions of the different types of pituitary adenomas were similar between both groups. There was also a slight, but expected, difference in the number of surgical operations. The majority of patients had undergone at least one procedure, apart from a small subset of 50 patients in the IRR group $(10 \%)$, who had received radiotherapy alone. Repeat surgery, because of recurrent or residual tumour, was carried out in $18 \%$ of both IRR and non-IRR patients.

There were no significant differences between IRR and non-IRR groups in terms of smoking habits or co-morbidities at baseline, including cardiovascular and cerebrovascular disease, diabetes mellitus (prevalence, $11.3 \%$ in IRR and 9.6\% in non-IRR) and non-pituitary neoplasms (data not shown).

\section{Baseline data}

Patients with a previous history of irradiation showed an equivalent degree of GHD to the non-IRR population, as demonstrated by equally reduced IGF-I concentrations and a similar $\mathrm{GH}$ peak in response to stimulation test (Table 2). Prior to the start of GH treatment, the two groups also did not differ in terms of systolic and diastolic blood pressure, BMI, waist circumference, FFM and serum total cholesterol, LDL cholesterol and triglycerides. IRR patients, however, had a greater impairment in QoL, as estimated by the QoLAGHDA score, a higher mean body fat mass, a lower level of HDL cholesterol and a lower BMC than non-IRR patients (Table 2). No difference in BMI and FFM was observed in either gender between IRR and non-IRR patients (data not shown). IRR female patients had a higher fat mass than non-IRR women $(29.7 \mathrm{vs} 23.5 \mathrm{~kg}$, $P<0.01)$, while the difference was not significant in men $(22.8$ vs $20.6 \mathrm{~kg})$.

\section{Effects of GH therapy}

After 1 year, the dose of GH was similar in both groups $(0.40 \pm 0.02 \mathrm{mg} /$ day, mean \pm s.D. $)$ and $\mathrm{GH}$ treatment induced significant and similar increases in serum IGF-I concentrations in both IRR and non-IRR patients, as well as similar improvements in QoL, as reflected by a decrease in the QoL-AGHDA score (Table 3; Fig. 1). Levels of total and LDL cholesterol were reduced in both groups; however, the reduction was greater in IRR patients (Table 3; Fig. 2). Changes in body composition determined by BIA were studied in a subgroup of 115 patients $(n=55$, IRR; $n=60$ non-IRR; Table 4$)$. FFM increased during GH therapy in both IRR and non-IRR patients, whereas body fat mass decreased similarly in

Table 1 Background characteristics of adult patients with severe GH deficiency (GHD), who were previously irradiated (IRR, $n=477$ ) or who have never received radiotherapy (non-IRR, $n=630$ ) for pituitary adenoma or craniopharyngioma.

\begin{tabular}{lllc}
\hline & IRR & Non-IRR & $\boldsymbol{P}$ value \\
\hline Total patients $(n)$ & 477 & 630 & $<0.05$ \\
Males/females $(n(\%))$ & $238 / 239(50 / 50)$ & $352 / 278(56 / 44)$ & $\mathrm{NS}$ \\
CO/AO GHD $(n(\%))$ & $54 / 423(11 / 89)$ & $56 / 574(9 / 91)$ & $<0.01$ \\
Age at disease onset (years) & $37 \pm 14$ & $41 \pm 15$ & $\mathrm{NS}$ \\
Age at GH start (years) & $49 \pm 12$ & $47 \pm 14$ & $<0.01$ \\
Estimated duration of GHD (years) & $11.5(3.5-23.2)$ & $4.7(1.3-17.3)$ & $\mathrm{NS}$ \\
Naive/semi-naive $(n(\%))$ & $405 / 72(85 / 15)$ & $562 / 68(88 / 12)$ & $<0.01^{\mathrm{b}}$ \\
Other hormone deficits $(0 / 1 / 2 / 3 / 4)(n(\%))$ & $31 / 60 / 79 / 220 / 87(6 / 13 / 17 / 46 / 18)$ & $43 / 85 / 92 / 210 / 200(7 / 13 / 15 / 33 / 32)$ & $\mathrm{NS}$ \\
Number of surgeries $(0 / 1 / 2 / 3)(n(\%))$ & $50 / 338 / 67 / 21(10 / 71 / 14 / 5)$ & $0 / 516 / 95 / 18(0 / 82 / 15 / 3)$ & $\mathrm{NS}$ \\
Craniopharyngioma $(n(\%))$ & $71(15)$ & $132(21 \%)$ & $\mathrm{NS}$ \\
NFPAs $(n(\%))$ & $232(48)$ & $300(48)$ & $\mathrm{NS}$ \\
Prolactinomas $(n(\%))$ & $80(17)$ & $97(15)$ & $\mathrm{NS}$ \\
ACTH-secreting adenomas $(n(\%))$ & $56(12)$ & $62(10)$ & $\mathrm{NS}$ \\
GH-secreting adenomas $(n(\%))$ & $24(5)$ & $11(2)$ & $\mathrm{NS}$ \\
Other types of pituitary adenomas $(n(\%))$ & $14(3)$ & $28(4)$ & \\
\hline
\end{tabular}

Data are shown as numbers of patients, percentages, means \pm s.D. or ${ }^{\mathrm{a}}$ median (10th and 90th percentiles) for non-normally distributed values. ${ }^{\mathrm{b}}$ Comparison between the mean number of deficiencies per group. ACTH, adrenocorticotrophin; AO, adult-onset; CO, childhood-onset; NFPA, non-functioning pituitary adenoma; NS, no significant difference between groups. 
Table 2 Baseline clinical and biochemical parameters in adult patients with severe GHD, who were previously irradiated (IRR) or who have never received radiotherapy (non-IRR) for pituitary adenoma or craniopharyngioma.

\begin{tabular}{|c|c|c|c|c|c|}
\hline & \multicolumn{2}{|r|}{ IRR } & \multicolumn{2}{|r|}{ Non-IRR } & \multirow[b]{2}{*}{$P$ value } \\
\hline & $n$ & Mean or median ${ }^{a}$ & $n$ & Mean or median ${ }^{a}$ & \\
\hline GH peak to stimulation test $(\mu \mathrm{g} / \mathrm{l})$ & 477 & $0.40(0.07-1.67)^{a}$ & 630 & $0.50(0.10-1.60)^{a}$ & NS \\
\hline IGF-I SDS & 402 & $-1.72 \pm 1.40$ & 471 & $-1.92 \pm 1.52$ & NS \\
\hline QoL-AGHDA score ${ }^{b}$ & 389 & $10.4 \pm 5.9$ & 472 & $9.3 \pm 6.5$ & $<0.02$ \\
\hline Body mass index & 477 & $29.2 \pm 6.6$ & 630 & $29.0 \pm 5.0$ & NS \\
\hline Systolic blood pressure (mmHg) & 474 & $128 \pm 22$ & 608 & $130 \pm 24$ & NS \\
\hline Diastolic blood pressure $(\mathrm{mmHg})$ & 474 & $80 \pm 21$ & 608 & $80 \pm 22$ & NS \\
\hline Lean body mass ${ }^{c}(\mathrm{~kg})$ & 160 & $55.0(54.4-58.5)^{\mathrm{a}}$ & 214 & $58.7(55.9-59.5)^{\mathrm{a}}$ & NS \\
\hline Fat mass ${ }^{c}(\mathrm{~kg})$ & 160 & $25.6(26.2-29.6)^{\mathrm{a}}$ & 214 & $21.8(23.5-26.9)^{\mathrm{a}}$ & $<0.001$ \\
\hline Total cholesterol $(\mathrm{mmol} / \mathrm{l})$ & 389 & $6.07 \pm 1.19$ & 447 & $6.02 \pm 1.27$ & NS \\
\hline HDL-cholesterol (mmol/l) & 391 & $1.22 \pm 0.40$ & 448 & $1.27 \pm 0.42$ & $<0.05$ \\
\hline LDL-cholesterol (mmol/l) & 367 & $3.86 \pm 1.18$ & 414 & $3.79 \pm 1.05$ & NS \\
\hline Bone mineral content ${ }^{\mathrm{d}}(\mathrm{kg})$ & 82 & $2.40(2.31-3.60)^{\mathrm{a}}$ & 113 & $2.80(2.61-4.04)^{a}$ & $<0.01$ \\
\hline
\end{tabular}

${ }^{\mathrm{a}}$ Data are shown as mean \pm standard deviation (s.D.) or as median (10th and 90th percentiles) for the non-normally distributed variables (GH peak, lean body mass, fat mass, bone mineral content). ${ }^{b}$ A lower Quality of Life Assessment of GHD in Adults (QoL-AGHDA) score means a better quality of life. ${ }^{\mathrm{c}}$ Measured by bioimpedance. ${ }^{\mathrm{d}}$ Measured by dual-energy X-ray absorptiometry. HDL, high-density lipoprotein; IGF-I, insulin-like growth factor I; LDL, low-density lipoprotein.

both groups. BMI was slightly reduced in the IRR group but not in patients who had not previously received irradiation. There was no significant change in triglycerides, HDL cholesterol, waist circumference and BMC in either group (Tables 3 and 4, and data not shown).

After 2 years of GH treatment, the mean GH dose was unchanged and remained similar in both groups $(0.40 \pm$ $0.02 \mathrm{mg} /$ day, mean \pm s.D.). The effects of GH therapy on IGF-I SDS, QoL-AGHDA score and lipid profile were maintained in both IRR and non-IRR patients (Table 3; Figs 1 and 2) and the reductions observed in serum total and LDL-cholesterol in IRR patients remained greater $(P<0.01)$ than those observed in non-IRR patients. A similar decrease in fat mass was also observed in both groups after 2 years, whereas changes in FFM were attenuated and no longer significant in IRR and non-IRR patients (Table 4). BMI was unchanged in both groups compared with baseline and the BMC had increased significantly, by $0.10 \mathrm{~kg}$ after 2 years in each group $(P<0.05)$. Interestingly, despite improvements in the QoL-AGHDA score in both groups, the relative difference in score observed at baseline between the IRR and nonIRR patients was maintained over the 2 years of $\mathrm{GH}$ treatment, while fat mass, HDL cholesterol and BMC no longer differed between the two groups (data not shown).

\section{Discussion}

To our knowledge, this is the first study to assess the impact of prior pituitary irradiation for hypothalamic-pituitary

Table 3 Changes in laboratory parameters and QoL-AGHDA score after 1 and 2 years of GH therapy in adult patients with severe GHD, who were previously irradiated (IRR) or who have never received radiotherapy (non-IRR) for pituitary adenoma or craniopharyngioma.

\begin{tabular}{|c|c|c|c|c|c|c|c|c|}
\hline & \multicolumn{4}{|c|}{ Treatment effects after 1 year $^{a}$} & \multicolumn{4}{|c|}{ Treatment effects after 2 years ${ }^{a}$} \\
\hline & $n$ & Mean \pm S.D. & $P$ vs baseline ${ }^{\mathrm{b}}$ & $\begin{array}{l}P \text { between } \\
\text { groups }^{b}\end{array}$ & $n$ & Mean \pm S.D. & $P$ vs baseline ${ }^{\mathrm{b}}$ & $\begin{array}{l}P \text { between } \\
\text { groups }^{b}\end{array}$ \\
\hline \multicolumn{9}{|l|}{ IGF-I (SDS) } \\
\hline IRR & 168 & $2.18 \pm 1.30$ & $<0.001$ & 0.67 & 98 & $2.41 \pm 1.52$ & $<0.001$ & 0.45 \\
\hline Non-IRR & 171 & $2.25 \pm 1.40$ & $<0.001$ & & 103 & $2.56 \pm 1.32$ & $<0.001$ & \\
\hline \multicolumn{9}{|c|}{ Total cholesterol $(\mathrm{mmol} / \mathrm{l})$} \\
\hline IRR & 144 & $-0.48 \pm 0.88$ & $<0.001$ & 0.039 & 87 & $-0.73 \pm 0.85$ & $<0.001$ & 0.003 \\
\hline Non-IRR & 153 & $-0.26 \pm 0.91$ & $<0.001$ & & 90 & $-0.33 \pm 0.95$ & $<0.001$ & \\
\hline \multicolumn{9}{|c|}{ LDL-cholesterol (mmol/l) } \\
\hline IRR & 129 & $-0.46 \pm 0.81$ & $<0.001$ & 0.027 & 81 & $-0.71 \pm 0.79$ & $<0.001$ & 0.007 \\
\hline Non-IRR & 142 & $-0.26 \pm 0.78$ & $<0.001$ & & 84 & $-0.37 \pm 0.82$ & $<0.001$ & \\
\hline \multicolumn{9}{|c|}{ HDL-cholesterol (mmol/l) } \\
\hline IRR & 144 & $0.00 \pm 0.22$ & 0.61 & 0.74 & 87 & $-0.03 \pm 0.22$ & 0.13 & 0.72 \\
\hline Non-IRR & 153 & $0.01 \pm 0.26$ & 0.69 & & 90 & $-0.02 \pm 0.30$ & 0.66 & \\
\hline \multicolumn{9}{|l|}{ QoL-AGHDA } \\
\hline IRR & 146 & $-4.5 \pm 5.8$ & $<0.001$ & 0.15 & 94 & $-4.5 \pm 6.1$ & $<0.001$ & 0.27 \\
\hline Non-IRR & 144 & $-3.4 \pm 5.0$ & $<0.001$ & & 87 & $-3.6 \pm 5.2$ & $<0.001$ & \\
\hline
\end{tabular}

${ }^{\text {aD }}$ ata are shown as change of absolute values in the same individuals compared with baseline; information missing in several patients in both groups. ${ }^{\text {b } P a i r e d ~}$ $t$-tests (normally distributed values). HDL, high-density lipoprotein; IGF-I, insulin-like growth factor-I; LDL, low-density lipoprotein; QoL-AGHDA, Quality of Life Assessment of GHD in Adults. 
Irradiated

Non-irradiated

${ }^{*} P<0.001$ versus baseline
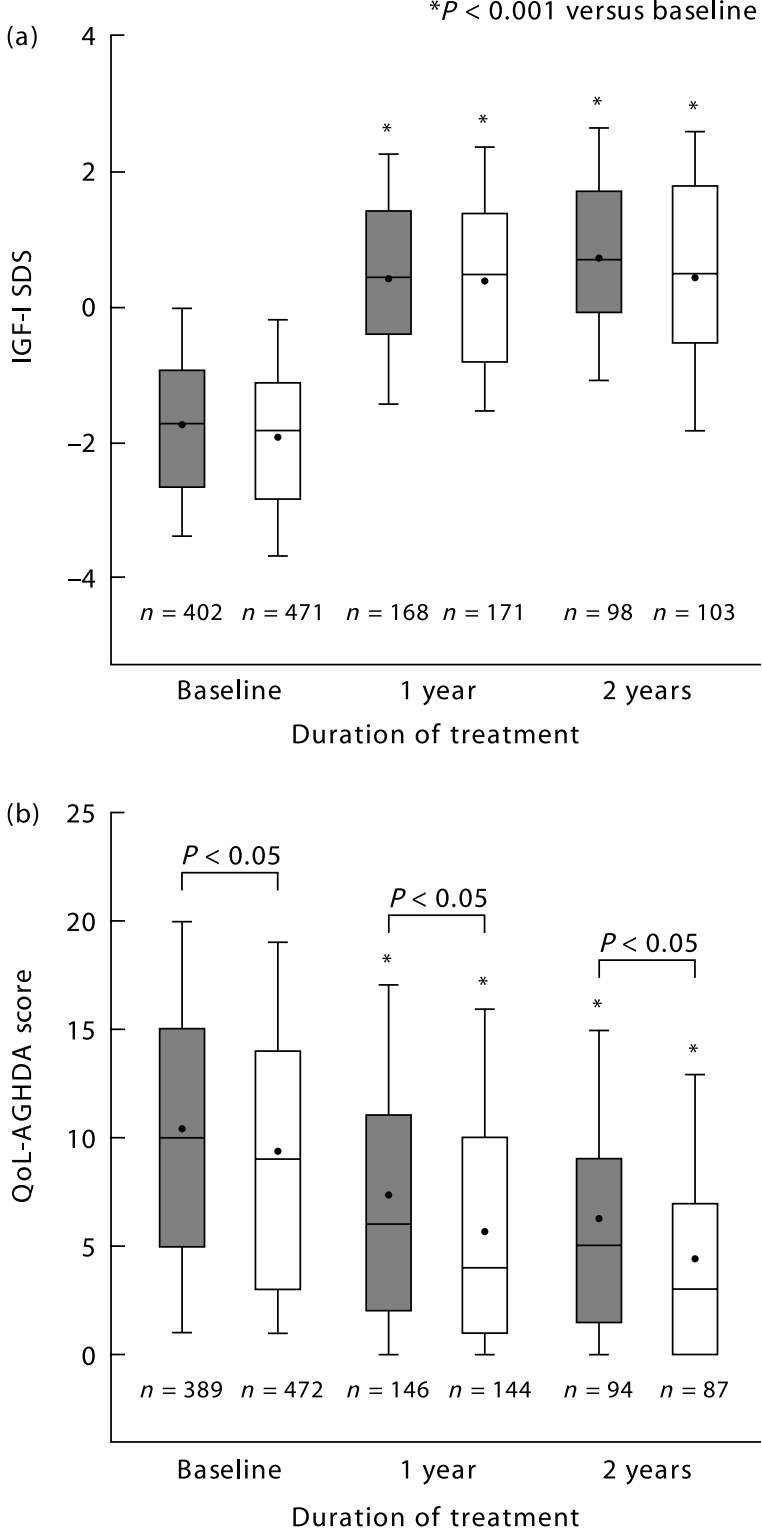

Figure 1 (a) Insulin-like growth factor-I SDS and (b) Quality of Life Assessment of GH deficiency (GHD) in Adults score at baseline and after 1 and 2 years of GH therapy in adult patients with severe GHD, who were previously irradiated or who have never received radiotherapy for pituitary adenoma or craniopharyngioma. Data shown are mean (black dots), median, 10th, 25th, 75th and 90th percentiles.

disease on the effects of GH replacement therapy in adult hypopituitary patients. Despite available evidence that $\mathrm{GH}$ is beneficial in GH-deficient adults (12-14), little was known concerning these effects in irradiated patients. One small study had shown that physiological GH replacement therapy induced only minor improvements in body composition, lipid profile and bone mineral
Irradiated

Non-irradiated

${ }^{*} P<0.001$ versus baseline
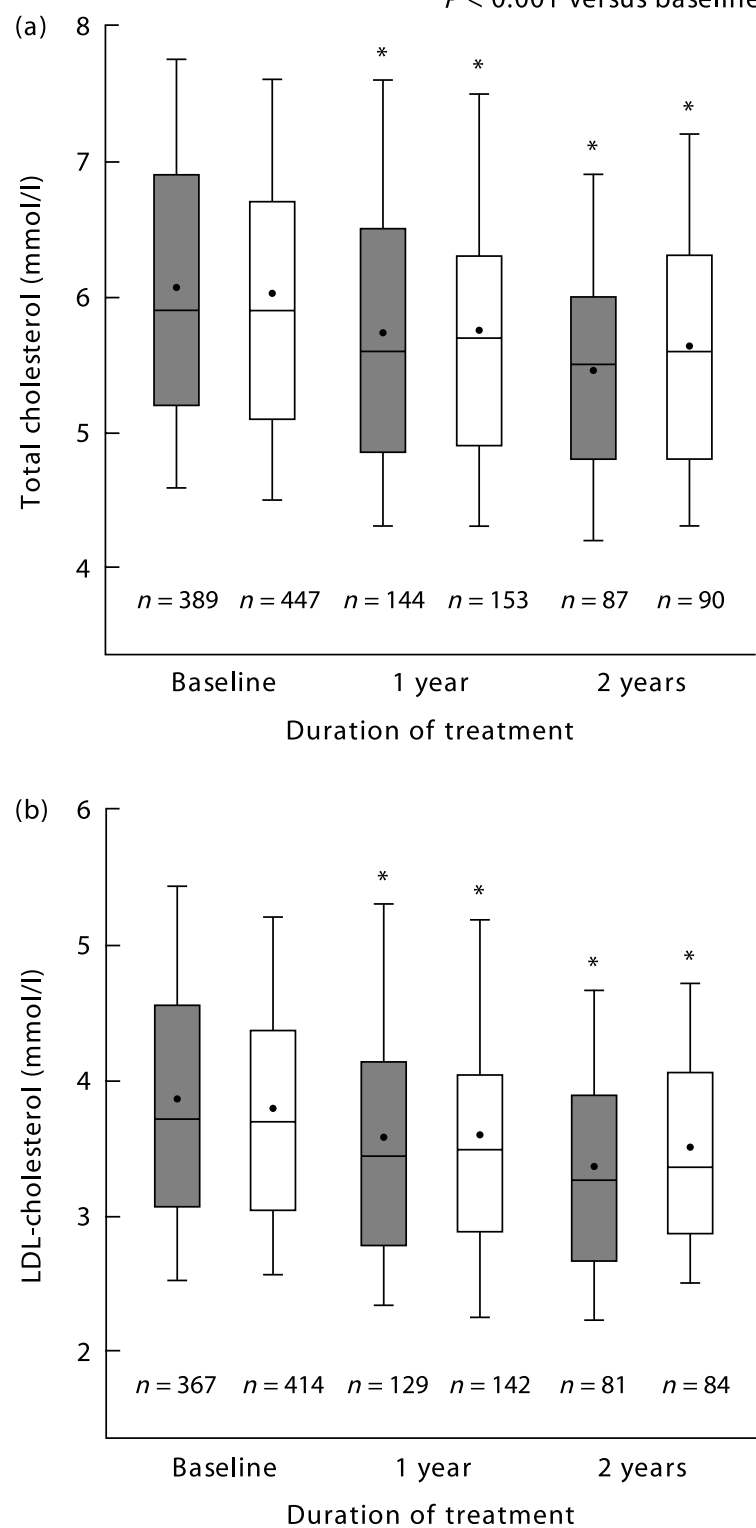

Figure 2 (a) Total cholesterol and (b) low-density lipoprotein (LDL) cholesterol at baseline and after 1 and 2 years of GH therapy in adult patients with severe GHD, who were previously irradiated for or who have never received radiotherapy for pituitary adenoma or craniopharyngioma. Data shown are mean (black dots), median, 10th, 25th, 75th and 90th percentiles.

density in young GH-deficient adult survivors of childhood cancer previously treated by cranial irradiation (21). Our study demonstrates, however, that adult GH-deficient patients who have been irradiated for pituitary adenoma or craniopharyngioma, respond equally well to GH as patients who have never received pituitary irradiation. 
Table 4 Changes of anthropometric parameters and bone mineral content (BMC) after 1 and 2 years of GH therapy in adult patients with severe GHD, who were previously irradiated (IRR) or who have never received radiotherapy (non-IRR) for pituitary adenoma or craniopharyngioma.

\begin{tabular}{|c|c|c|c|c|c|c|c|c|}
\hline & \multicolumn{4}{|c|}{ Treatment effects after 1 year $^{a}$} & \multicolumn{4}{|c|}{ Treatment effects after 2 years ${ }^{b}$} \\
\hline & $n$ & $\begin{array}{c}\text { Median } \\
\text { (P10; P90) }\end{array}$ & $P$ vs baseline & $\begin{array}{c}P \text { between } \\
\text { groups }\end{array}$ & $n$ & $\begin{array}{c}\text { Median } \\
\text { (P10-P90) }\end{array}$ & $P$ vs baseline & $\begin{array}{c}P \text { between } \\
\text { groups }\end{array}$ \\
\hline \multicolumn{9}{|l|}{ BMI $\left(\mathrm{kg} / \mathrm{m}^{2}\right)$} \\
\hline IRR & 210 & $-0.14(-2.05 ; 1.44)$ & $<0.005$ & 0.67 & 127 & $0.14(-2.48 ; 2.51)$ & 0.74 & 0.73 \\
\hline Non-IRR & 248 & $0.00(-1.59 ; 2.01)$ & 0.39 & & 137 & $0.06(-1.62 ; 2.14)$ & 0.31 & \\
\hline \multicolumn{9}{|c|}{ Fat mass $(\mathrm{kg})^{\mathrm{C}}$} \\
\hline IRR & 54 & $-1.55(-7.90 ; 3.40)$ & 0.016 & 0.039 & 28 & $-2.15(-8.10 ; 4.30)$ & 0.071 & 0.95 \\
\hline Non-IRR & 59 & $-1.50(-11.8 ; 5.30)$ & 0.020 & & 24 & $-1.30(-7.30 ; 2.00)$ & 0.025 & \\
\hline \multicolumn{9}{|c|}{ Fat-free mass $(\mathrm{kg})^{\mathrm{C}}$} \\
\hline IRR & 55 & $1.90(-3.80 ; 5.30)$ & 0.016 & 0.027 & 28 & $1.10(-6.60 ; 6.60)$ & 0.48 & 0.59 \\
\hline $\begin{array}{l}\text { Non-IRR } \\
\text { BMC }(\mathrm{kg})^{\mathrm{d}}\end{array}$ & 61 & $1.15(-4.00 ; 10.40)$ & 0.011 & & 24 & $1.25(-6.30 ; 10.10)$ & 0.15 & \\
\hline IRR & 23 & $0.00\left({ }^{*} 0.10 ; 0.10\right)$ & 0.36 & 0.74 & 18 & $0.10(-0.10 ; 0.10]$ & 0.0013 & 0.77 \\
\hline Non-IRR & 37 & $0.00[-0.20 ; 0.10]$ & 0.063 & & 23 & $0.10[-0.20 ; 0.20]$ & 0.012 & \\
\hline
\end{tabular}

${ }^{a}$ Data are shown as change of absolute values in the same individuals compared with baseline; information is missing in several patients in both groups ${ }^{b}$ Wilcoxon rank-sum tests (non-normally distributed values). ${ }^{\mathrm{c}}$ Results derived from bioelectrical impedance analysis. ${ }^{\mathrm{d}}$ Results derived from dual-energy X-ray absorptiometry.

BMC, bone mineral content; BMI, body mass index. P10, 10th percentile; P90, 90th percentile.

Before the initiation of GH treatment, IRR and nonIRR patients were similar in terms of the severity of GHD. Repeat surgery (presumably for regrowth of the tumour), which is known to be associated with increased disease severity and mortality in patients with pituitary macroadenomas (22), was performed in a similar number of patients in each group. Since the proportion of patients with craniopharyngioma was slightly higher in the non-IRR group, the data were corrected for the presence of craniopharyngioma, as this condition has previously been shown to cause more profound hypothalamic damage and an increased morbidity and mortality (23). There were also slightly more men in the group of non-IRR patients. Since the gender difference in sensitivity to GH is known - women being more resistant and requiring higher $\mathrm{GH}$ doses to achieve normal IGF-I concentrations (24) - data analysis was also corrected for gender and similar results were obtained in male and female IRR patients. Non-IRR patients had a higher number of pituitary deficits, mainly diabetes insipidus, and a significantly shorter estimated duration of GHD prior to entry into KIMS than IRR patients. None of these differences are sufficient, however, to preclude a comparative analysis of the response to $\mathrm{GH}$ treatment between the two groups.

Prior to the start of $\mathrm{GH}$ treatment, the patients exhibited the characteristics of severe adult GHD, including reduced IGF-I SDS, FFM, BMC and OoL, increased BMI and fat mass and an abnormal lipid profile. Individuals with a previous history of pituitary irradiation, however, had a greater impairment in their QoL, a higher body fat mass, lower HDL cholesterol levels and a lower BMC than non-IRR patients. The observed differences may have resulted from the longer duration of untreated GHD in the IRR group or from direct detrimental effects of radiotherapy on the brain. It has previously been shown that radiotherapy may have an effect on QoL. Page et al. also reported higher levels of depression and emotional lability in a group of IRR GH-deficient patients compared with patients who had undergone mastoid surgery, but the effects of GHD and irradiation could not be distinguished (25). In contrast, in a small cohort of patients with hypopituitarism and GHD, using a different questionnaire, Wallymahmed and colleagues could not find any significant differences in QoL between those who had received radiotherapy and those who had not received radiotherapy (26).

In the current study, GH replacement therapy with a comparable daily dose of $\mathrm{GH}$ (median, $0.40 \mathrm{mg}$ ) for 1 year produced a similar improvement in the characteristics of severe GHD in IRR and non-IRR adults. Thus, GH induced similar increases in IGF-I and FFM, a similar reduction in fat mass, and a comparable improvement in QoL in both groups. These positive effects of GH treatment were maintained during the first 2 years of treatment and, by the end of the second year of $\mathrm{GH}$ treatment, BMC had also increased equally in both groups. Moreover, 2 years of GH therapy attenuated the baseline differences observed in fat mass, HDL cholesterol and BMC between IRR and non-IRR subjects, but was unable to diminish the relative difference in QoL, which remained worse in IRR than in non-IRR patients throughout the study period, despite an overall improvement in QoL in both groups.

In comparison with patients who had never received radiotherapy, IRR patients showed a better response with respect to the lipid profile, the reduction of total 
and LDL cholesterol being significantly greater in IRR patients. This difference was maintained after 2 years of $\mathrm{GH}$ treatment. GH-deficient patients are known to have higher total and LDL cholesterol than normal controls, while HDL cholesterol often tends to be lower than expected; these abnormalities are reversed by $\mathrm{GH}$ treatment $(27,28)$. The mechanisms behind these GH effects on dyslipidaemia are not fully understood, but are likely to involve a stimulatory effect on hepatic LDL receptors and an increase in LDL clearance rate (29). There is, however, no obvious explanation for the observed effects of irradiation on these mechanisms.

To test our hypothesis, the study required a very large patient population, which is not available in individual clinics and can only be provided by central databases such as KIMS. Accepting the well-known limitations of the retrospective analysis of observational surveys, this analysis clearly shows that prior pituitary irradiation does not significantly compromise the beneficial effects of GH replacement therapy.

\section{References}

1 Gittoes NJ, Bates AS, Tse W, Bullivant B, Sheppard MC, Clayton RN \& Stewart PM. Radiotherapy for non-functioning pituitary tumours. Clinical Endocrinology 199848 331-337.

2 Plowman PN. Pituitary adenoma radiotherapy-when, who and how? Clinical Endocrinology 199951 265-271.

3 Boelaert K \& Gittoes NJ. Radiotherapy for non-functioning pituitary adenomas. European Journal of Endocrinology $2001 \mathbf{1 4 4}$ 569-575.

4 Brada M, Ford D, Ashley S, Bliss JM, Crowley S, Mason M, Rajan B $\&$ Traish D. Risk of second brain tumour after conservative surgery and radiotherapy for pituitary adenoma. British Medical Journal 1992304 1343-1346.

5 Peace KA, Orme SM, Sebastian JP, Thompson AR, Barnes S, Ellis A \& Belchetz PE. The effect of treatment variables on mood and social adjustment in adult patients with pituitary disease. Clinical Endocrinology 199746 445-450.

6 Erfurth EM, Bulow B, Mikoczy Z, Svahn-Tapper G \& Hagmar L. Is there an increase in second brain tumours after surgery and irradiation for a pituitary tumour? Clinical Endocrinology 200155 613-616.

7 Brada M, Ashley S, Ford D, Traish D, Burchell L \& Rajan B. Cerebrovascular mortality in patients with pituitary adenoma. Clinical Endocrinology 200257 713-717.

8 AyukJ, Clayton RN, Holder G, Sheppard MC, Stewart PM \& Bates AS. Growth hormone and pituitary radiotherapy, but not serum insulinlike growth factor-I concentrations, predict excess mortality in patients with acromegaly. Journal of Clinical Endocrinology and Metabolism 200489 1613-1617.

9 Littley MD, Shalet SM, Beardwell CG, Ahmed SR, Applegate G \& Sutton ML. Hypopituitarism following external radiotherapy for pituitary tumours in adults. Quarterly Journal of Medicine 198970 $145-160$

10 Darzy KH \& Shalet SM. Pathogenesis and clinical presentation of radiation-induced hypopituitarism. In Central and Peripheral Mechanisms in Pituitary Disease, pp 51-69. Eds DL Kleinberg \& DR Clemmons, Bristol: Bioscientifica, 2002.

11 Shalet SM. Radiation and pituitary dysfunction. New England Journal of Medicine 1993328 131-133.

12 Carroll PV, Christ ER, Bengtsson BA, Carlsson L, Christiansen JS, Clemmons D, Hintz R, Ho K, Laron Z, Sizonenko P, Sonksen PH,
Tanaka $\mathrm{T} \&$ \& Thorne $\mathrm{M}$. Growth hormone deficiency in adulthood and the effects of growth hormone replacement: a review. Growth Hormone Research Society Scientific Committee. Journal of Clinical Endocrinology and Metabolism $1998 \mathbf{8 3}$ 382-395.

13 Abs R, Bengtsson BA, Hernberg-Stahl E, Monson JP, Tauber JP, Wilton P \& Wuster C. GH replacement in 1034 growth hormone deficient hypopituitary adults: demographic and clinical characteristics, dosing and safety. Clinical Endocrinology 199950 703713.

14 Drake WM, Howell SJ, Monson JP \& Shalet SM. Optimizing GH therapy in adults and children. Endocrine Reviews 200122 $425-450$.

15 Noad R, Narayanan KR, Howlett T, Lincoln NB \& Page RC. Evaluation of the effect of radiotherapy for pituitary tumours on cognitive function and quality of life. Clinical Oncology 200416 233-277.

16 Muller HL, Bruhnken G, Emser A, Faldum A, Etavard-Gorris N, Gebhardt U, Kolb R \& Sorensen N. Longitudinal study on quality of life in 102 survivors of childhood craniopharyngioma. Child's Nervous System 200521 975-980.

17 de Boer H, Blok GJ, Voerman B, de Vries P, Popp-Snijders C \& vab der Veen E. The optimal growth hormone replacement dose in adults, derived from bioimpedance analysis. Journal of Clinical Endocrinology and Metabolism 199580 2069-2076.

18 Friedewald WT, Levy RI \& Fredrickson DS. Estimation of the concentration of low-density lipoprotein cholesterol in plasma, without use of the preparative ultracentrifuge. Clinical Chemistry 197218 499-502.

19 McKenna SP, Doward LC, Alonso J, Kohlmann T, Niero M, Prieto L $\&$ Wiren L. The QoL-AGHDA: an instrument for the assessment of quality of life in adults with growth hormone deficiency. Quality of Life Research 19998 373-383.

20 Wiren L, Whalley D, Mckenna S \& Wilhelmsen L. Application of a disease-specific, quality of life measure (QoL-AGHDA) in growth hormone-deficient adults and a random population sample in Sweden: validation of the measure by Rasch analysis. Clinical Endocrinology 200052 143-152.

21 Murray RD, Darzy KH, Gleeson HK \& Shalet SM. GH-deficient survivors of childhood cancer: GH replacement during adult life. Journal of Clinical Endocrinology and Metabolism $2002 \mathbf{8 7}$ 129-135.

22 Erfurth EM, Bulow B, Nordstrom CH, Mikoczy Z, Hagmar L \& Stromberg U. Doubled mortality rate in irradiated patients reoperated for regrowth of a macroadenoma of the pituitary gland. European Journal of Endocrinology 2004150 497-502.

23 Verhelst J, Kendall-Taylor P, Erfurth EM, Price DA, Geffner M, Koltowska-Haggstrom M, Jonsson PJ, Wilton P \& Abs R. Baseline characteristics and response to 2 years of growth hormone $(\mathrm{GH})$ replacement of hypopituitary patients with $\mathrm{GH}$ deficiency due to adult-onset craniopharyngioma in comparison with patients with nonfunctioning pituitary adenoma: data from KIMS (Pfizer International Metabolic Database). Journal of Clinical Endocrinology and Metabolism 200590 4636-4643.

24 Mukherjee A, Monson JP, Jonsson PJ, Trainer PJ \& Shalet SM. Seeking the optimal target range for insulin-like growth factor I during the treatment of adult growth hormone disorders. Journal of Clinical Endocrinology and Metabolism $2003 \mathbf{8 8}$ 5865-5870.

25 Page RC, Hammersley MS, Burke CW \& Wass JA. An account of the quality of life of patients after treatment for non-functioning pituitary tumours. Clinical Endocrinology 1997 46 401-406.

26 Wallymahmed ME, Foy P \& MacFarlane IA. The quality of life of adults with growth hormone deficiency: comparison with diabetic patients and control subjects. Clinical Endocrinology $199951333-$ 338.

27 Cuneo RC, Salomon F, Watts GF, Hesp R \& Sonksen PH. Growth hormone treatment improves serum lipids and lipoproteins in adults with growth hormone deficiency. Metabolism $1993 \mathbf{4 2}$ 1519-1523. 
28 Cummings MH, Christ E, Umpleby AM, Albany E, Wierzbicki A, Lumb PJ, Sonksen PH \& Russell-Jones DL. Abnormalities of very low density lipoprotein apolipoprotein B-100 metabolism contribute to the dyslipidaemia of adult growth hormone deficiency. Journal of Clinical Endocrinology and Metabolism $1997 \mathbf{8 2}$ 2010-2013.

29 Christ ER, Cummings MH, Jackson N, Stolinski M, Lumb PJ, Wierzbicki AS, Sonksen PH, Russell-Jones DL \& Umpleby AM. Effects of growth hormone $(\mathrm{GH})$ replacement therapy on low-density lipoprotein apolipoprotein B100 kinetics in adult patients with GH deficiency: a stable isotope study. Journal of Clinical Endocrinology and Metabolism 200489 1801-1807.

Received 24 January 2006

Accepted 15 May 2006 